\title{
Characterization of pure cultures isolated from sulfamethoxazole-acclimated activated sludge with respect to taxonomic identification and sulfamethoxazole biodegradation potential
}

\author{
Bastian Herzog ${ }^{1 *}$, Hilde Lemmer ${ }^{2}$, Harald Horn ${ }^{3}$ and Elisabeth Müller ${ }^{1}$
}

\begin{abstract}
Background: Sulfamethoxazole (SMX, sulfonamide antibiotic) biodegradation by activated sludge communities (ASC) is still only partly understood. The present work is focusing on nine different bacteria species capable of SMX biodegradation that were isolated from SMX-acclimated ASC.

Results: Initially 110 pure cultures, isolated from activated sludge, were screened by UV-absorbance measurements (UV-AM) for their SMX biodegradation potential. Identification via almost complete $16 \mathrm{~S}$ rRNA gene sequencing revealed five Pseudomonas spp., one Brevundimonas sp., one Variovorax sp. and two Microbacterium spp.. Thus seven species belonged to the phylum Proteobacteria and two to Actinobacteria. These cultures were subsequently incubated in media containing $10 \mathrm{mg} \mathrm{L}^{-1} \mathrm{SMX}$ and different concentrations of carbon (sodium-acetate) and nitrogen (ammonium-nitrate). Different biodegradation patterns were revealed with respect to media composition and bacterial species. Biodegradation, validated by LC-UV measurements to verify UV-AM, occurred very fast with $2.5 \mathrm{mg} \mathrm{L}^{-1} \mathrm{~d}^{-1} \mathrm{SMX}$ being biodegraded in all pure cultures in, for UV-AM modified, R2A-UV medium under aerobic conditions and room temperature. However, reduced and different biodegradation rates were observed for setups with SMX provided as co-substrate together with a carbon/nitrogen source at a ratio of DOC:N - 33:1 with rates ranging from 1.25 to $2.5 \mathrm{mg} \mathrm{L}^{-1} \mathrm{~d}^{-1}$.
\end{abstract}

Conclusions: Media containing only SMX as carbon and nitrogen source proved the organisms' ability to use SMX as sole nutrient source where biodegradation rates decreased to $1.0-1.7 \mathrm{mg} \mathrm{L}^{-1} \mathrm{~d}^{-1}$. The different taxonomically identified species showed specific biodegradation rates and behaviours at various nutrient conditions. Readily degradable energy sources seem to be crucial for efficient SMX biodegradation.

Keywords: Batch setups, Wastewater treatment plants, Xenobiotics, UV-absorbance, Pharmaceuticals, Phylogenetic analyses, Sulfamethoxazole

\section{Background}

The widespread usage, disposal all around the world and a consumption of up to $200,000 \mathrm{t}$ per year, makes the various groups of antibiotics an important issue for micropollutants risk assessment [1,2]. Their discharge and thus presence in the environment has become of major concern for environmental protection strategies.

\footnotetext{
* Correspondence: b.herzog@tum.de

'Chair of Urban Water Systems Engineering, Technische Universität

München, Am Coulombwall, D-85748 Garching, Germany

Full list of author information is available at the end of the article
}

Antibiotics are designed to inhibit microorganisms and therefore influence microbial communities in different ecosystems [3,4]. Monitoring programs have already shown that antibiotics can be found nearly everywhere in the environment, even in concentrations up to $\mu \mathrm{g} \mathrm{L}{ }^{-1}$ leading to antibiotic resistance in organisms [5-9]. Antibiotic resistance genes might be transferred to humanpathogenic organisms by horizontal gene-transfer and become a serious issue, especially multidrug resistance in bacteria [10-12].

\section{Biomed Central}

(c) 2013 Herzog et al.; licensee BioMed Central Ltd. This is an open access article distributed under the terms of the Creative Commons Attribution License (http://creativecommons.org/licenses/by/2.0), which permits unrestricted use, distribution, and reproduction in any medium, provided the original work is properly cited. 
Sulfamethoxazole (SMX) is one of the most often applied antibiotics [13]. The frequent use of SMX results in wastewater concentrations up to $\mu \mathrm{g} \mathrm{L} \mathrm{L}^{-1}$ and surface water concentrations in the ng $\mathrm{L}^{-1}$ scale [14-17]. Even in groundwater SMX was found at concentrations up to $410 \mathrm{ng} \mathrm{L}^{-1}$ [16]. These SMX concentrations might be too low for inhibitory effects as the $\mathrm{MIC}_{90}$ for $M$. tuberculosis was found to be $9.5 \mathrm{mg} \mathrm{L}^{-1}$ [18], but they might be high enough to function as signalling molecule to trigger other processes like quorum sensing in environmental microbial communities [19].

As shown by different studies [20-23], SMX can induce microbial resistances and reduce microbial activity and diversity arising the need for a better understanding of SMX biodegradation. SMX inflow concentrations in WWTPs in $\mu \mathrm{g} \mathrm{L}^{-1}$ combined with often partly elimination ranging from $0 \%$ to $90 \%[4,6,15,24]$ result in high effluent discharge into the environment. To predict the extent of removal knowledge about the responsible biodegrading microorganisms is implicitly required to optimize environmental nutrient conditions for SMX removal and degradation rates. It is known that SMX can be removed by photodegradation occurring mainly in surface waters $[25,26]$ and sorption processes in activated sludge systems [27]. However, biodegradation is, especially in WWTPs, probably the major removal process. Literature data focusing on SMX biodegradation in lab scale experiments with activated sludge communities and pure cultures showed a high fluctuation from almost complete SMX elimination $(9,28,29)$ to hardly any removal of SMX (30). The determined SMX biodegradation potential was clearly affected by nutrient supply. Therefore this study's emphasis is on clarifying the effect that addition of readily degradable carbon and/or nitrogen sources in some cases significantly enhanced SMX elimination (31) while in other cases supplementation showed no effect (28).

For this purpose pure culture were isolated from SMX-acclimated activated sludge communities and identified in respect to taxonomy and biodegradation capacity. Aerobic SMX biodegradation experiments with different species were carried out at various nutrient conditions to screen biodegradation potential and behaviour as a base for future research on biodegradation pathways.

\section{Results}

\section{SMX biodegradation}

Cultivation and evaluation of pure cultures biodegradation potential

Isolation of pure cultures was accomplished from SMXacclimated ASC. Growth of cultures on solid R2A-UV media, spiked with $10 \mathrm{mg} \mathrm{L}^{-1} \mathrm{SMX}$, was controlled every 24 hours. All morphologically different colonies were streaked onto fresh R2A-UV agar plates, finally resulting in 110 pure cultures. For identification of potential SMX biodegrading cultures, all 110 isolates were inoculated in $20 \mathrm{~mL}$ MSM-CN media. SMX biodegradation was controlled every two days. After two days a decrease in absorbance was already detected in 5 cultures followed by 7 more at day 4 and 6 while the remaining cultures showed no change. The experiment was stopped after 21 days revealing no further SMX biodegrading culture. A 50\% cutoff line defined a 50\% decrease in UVabsorbance being significant enough to be sure that the corresponding organisms showed biodegradation. 12 organisms showed a decrease in absorbance greater than $50 \%$ of initial value and were defined as potential SMX biodegrading organisms. They were taxonomically identified and used for subsequent biodegradation experiments.

Additionally, biodegradation of these 12 identified isolates was validated by LC-UV (Table 1). For cost efficiency only initial and end concentrations of SMX in the media were determined as absorbance values did not change any more. A decrease in SMX concentration from initially $10 \mathrm{mg} \mathrm{L}^{-1}$ to below $5 \mathrm{mg} \mathrm{L}^{-1}$ was detected for all 12 isolates (Table 1 ) after 10 days of incubation. It was proven that only 3 cultures eliminated all $10 \mathrm{mg} \mathrm{L}^{-1}$ SMX completely while the residual SMX concentrations for the remaining cultures ranged from 0.23 to $4.35 \mathrm{mg} \mathrm{L}^{-1}$ after 10 days of incubation.

\section{Taxonomic and phylogenetic identification of pure cultures}

All 12 cultures were identified by $16 \mathrm{~S}$ rRNA gene sequence analysis to evaluate their phylogenetic position and closest relative. Four cultures, SMX 332, 333, 336

\begin{tabular}{|c|c|}
\hline Pure culture & SMX conc. after 10 days $\left[\mathrm{mg} \mathrm{L}^{-1}\right]$ \\
\hline Brevundimonas sp. SMXB12 & 0.00 \\
\hline Microbacterium sp. SMXB24 & 0.00 \\
\hline Microbacterium sp. SMX348 & 0.00 \\
\hline Pseudomonas sp. SMX321 & 0.68 \\
\hline Pseudomonas sp. SMX330 & 0.68 \\
\hline Pseudomonas sp. SMX331 & 2.68 \\
\hline Pseudomonas sp. SMX 333* & 1.09 \\
\hline Pseudomonas sp. SMX 336* & 4.35 \\
\hline Pseudomonas sp. SMX $342^{*}$ & 1.09 \\
\hline Pseudomonas sp. SMX344* & 0.23 \\
\hline Pseudomonas sp. SMX345 & 1.58 \\
\hline Variovorax sp. SMX332 & 3.53 \\
\hline
\end{tabular}

*duplicate organisms. All but SMX344 were discarded.

Taxonomic identification succeeded with

BLAST (http://blast.ncbi.nlm.nih.gov/Blast.cgi). 
and 344, turned out to be the same organism closely related to Pseudomonas sp. He (AY663434) with a sequence similarity of 99\%. Only SMX 344 was kept for further experiments as it showed fastest biodegradation in pre-tests (Table 1). Hence, a total of 9 different bacterial species with SMX biodegradation capacity were obtained. Their accession numbers, genus names and their closest relatives as found in the NCBI database (http://blast.ncbi.nlm.nih.gov/Blast.cgi), are shown as a maximum likelihood-based phylogenetic tree (Figure 1) evaluated with $16 \mathrm{~S}$ rRNA gene sequence comparisons to calculate the most exact branching [28].

Seven of the nine isolates are affiliated within the phylum Proteobacteria represented by the classes Alpha-, Beta- and Gammaproteobacteria, while two belonged to the Phylum Actinobacteria.

The phylogenetic positions of the seven isolated pure cultures, affiliated within the phylum Proteobacteria, were located in the same tree (Figure 1A). Five different Pseudomonas spp. were identified and form two different clades representing a highly diverse group. Pseudomonas sp. SMX344 and 345 is building an individual cluster but belonged to the same group as SMX330 and 331. All four are closely related to $P$. fluorescens but SMX331 showed a remarkable difference. In contrast to the described Pseudomonas spp. above, Pseudomonas sp. SMX321 clusters together with $P$. putida and P. alcaligenes but forms an individual branch.

The other two Proteobacteria identified pure cultures belonged to the genera Variovorax (SMX332) and Brevundimonas (SMXB12). The isolated Variovorax SMX332 fell into the Variovorax paradoxus/boronicumulans group with a sequence similarity $>99 \%$ to $V$. paradoxus (EU169152).

The Brevundimonas sp. SMXB12 was clearly separated from its closest relatives Brevundimonas basaltis and B. lenta and formed its own branch.

Both Actinobacteria affiliated pure cultures were identified as Microbacterium spp. and were embedded in a new phylogenetic tree as their phylogenetic position was too far from the other isolates (Figure 1B). The two isolated species were affiliated to two different clades clearly separated from $M$. lacus and M. aurum. Microbacterium sp. SMXB24 fell into the same group as Microbacterium sp. $71 \mathrm{~K}$ and $M$. hatatonis but the branch length clearly showed separation. Microbacterium sp. SMX348 was closely related with a sequence similarity of $>99 \%$ to Microbacterium sp. BR1 which was found to biodegrade SMX in an acclimated membrane bioreactor [29].

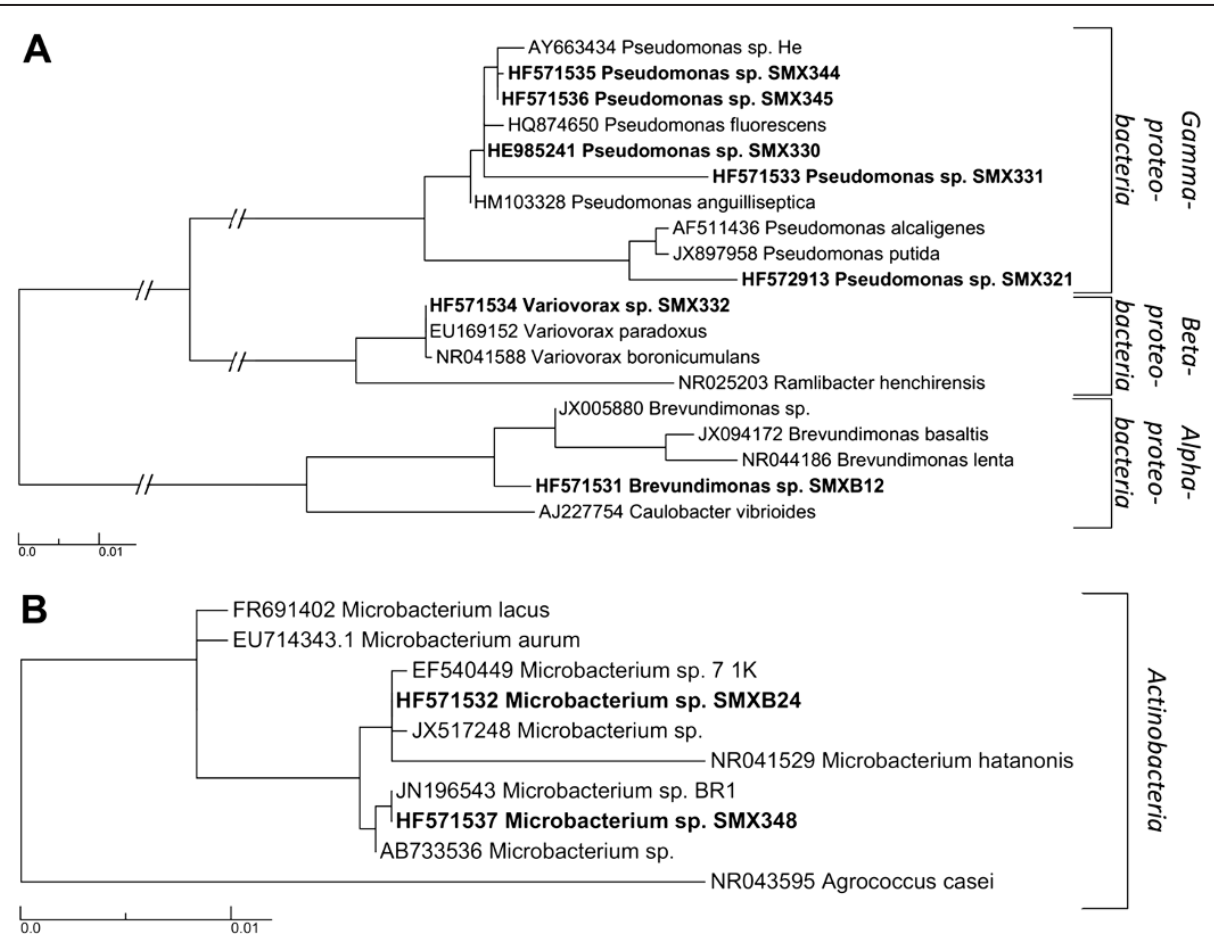

Figure 1 Maximum likelihood-based trees reflecting the phylogeny and diversity of the isolated nine species capable of SMX biodegradation based on nearly complete $16 \mathrm{~S}$ rRNA gene sequence comparisons. Phylogenetic tree calculated for A) Pseudomonas spp., Variovorax spp. and Brevundimonas spp. and B) for Microbacterium spp.. The tree shows the sequences obtained in this study (bold text) and their next published relatives according to the NCBI database (plain text). Numbers preceding taxonomic names represent EMBL sequence accession numbers. Scale bar indicates $0.01 \%$ estimated sequence divergence. 


\section{SMX biodegradation studies with pure cultures}

Setups with sterile biomass (heat-killed) and without biomass (abiotic control) proved SMX to be stable under the operating conditions. Therefore sorption onto biomass or other materials was shown to be negligible. Photodegradation was excluded by performing all experiments in the dark.

To characterize biodegradation ability and rate and evaluate an optimal nutrient environment for SMX utilization of the isolated and identified 9 pure cultures, subsequent experiments were performed. In the presence of readily degradable carbon and/or nitrogen sources (Figures 2 and 3) SMX was faster biodegraded compared to setups with SMX as sole carbon/nitrogen source (Figure 3). 54 setups (three media for each of the 9 cultures in duplicate setups) with different nutrient compositions were set up and SMX biodegradation rates were evaluated using UV-AM values (Table 2). Different SMX biodegradation patterns were observed proving that the presence or absence of readily degradable and complex nutrients significantly influenced biodegradation.

R2A-UV media were sampled once a day as it was assumed that biodegradation might be faster compared to the other two nutrient-poor media. Biodegradation rates of $2.5 \mathrm{mg} \mathrm{L}^{-1} \mathrm{~d}^{-1}$ were found for all nine species not showing any different biodegradation behaviors or patterns (Figure 4A). Although biomass growth affected background absorbance that increased with cell density, UV-AM could still be applied to monitor biodegradation as background absorbance was still in a measurable range.

In MSM-CN (Figure 2), offering only specific C- and $\mathrm{N}$-sources, the biodegradation rates ranged from 1.25 to $2.5 \mathrm{mg} \mathrm{L}^{-1} \mathrm{~d}^{-1}$ (deviations between the duplicate setups were below 1\%) showing clear differences for the different species, even for the five Pseudomonas spp.. While Pseudomonas sp. SMX321 biodegraded SMX with $2.5 \mathrm{mg} \mathrm{L}^{-1} \mathrm{~d}^{-1}$, Pseudomonas sp. SMX344 just showed a

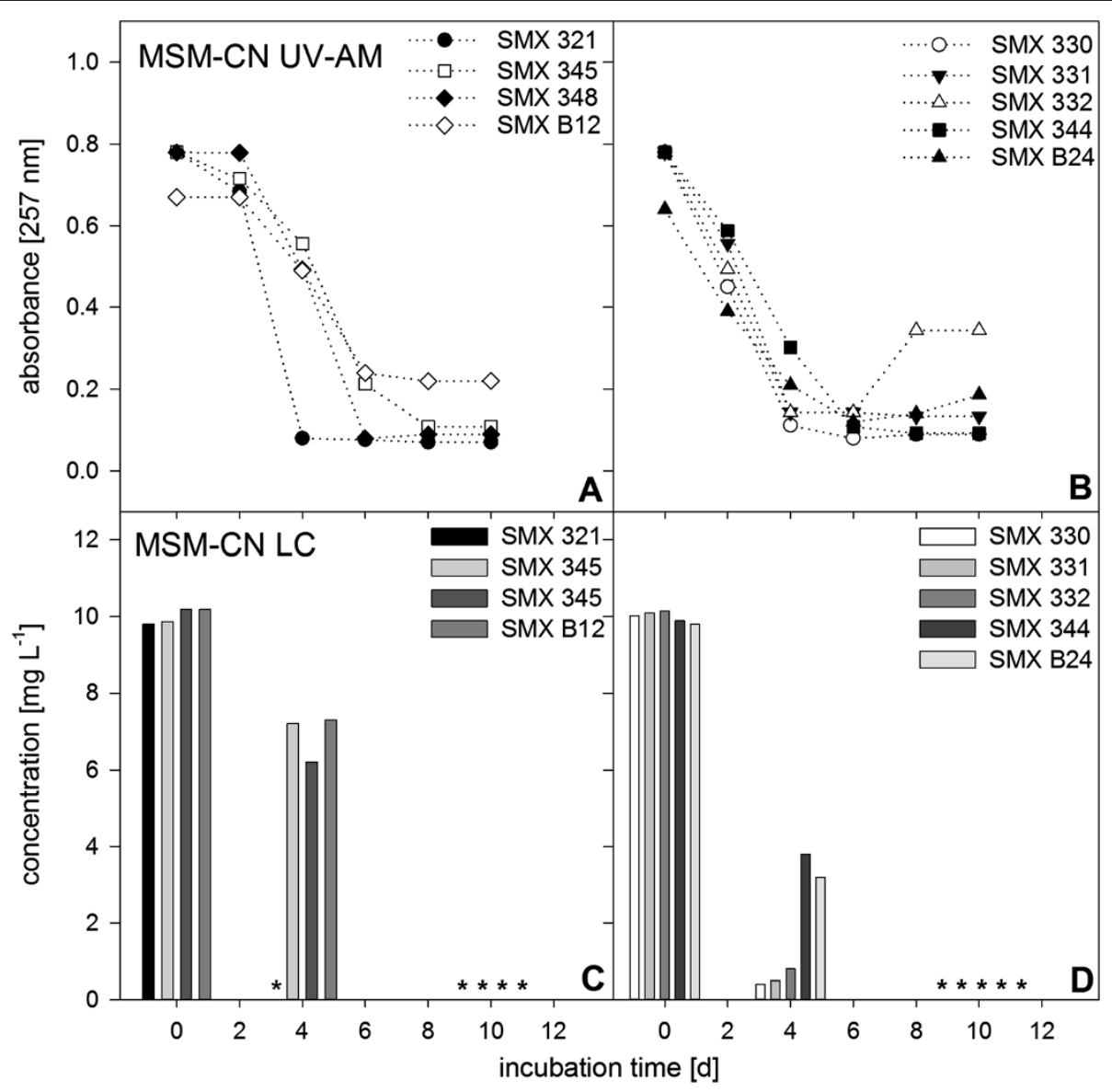

Figure 2 Aerobic SMX biodegradation patterns of pure cultures in MSM-CN media. A, B) measured with UV-AM, initial SMX concentration $10 \mathrm{mg} \mathrm{L}^{-1}$. C, D) LC-UV analyses of SMX concentrations in the used pure cultures in MSM-CN. Determination was performed at experimental startup, after 4 and 10 days to verify UV-AM values. Asterisks indicate measured values below limit of detection. Shown are mean values of SMX absorbance in duplicate experiments. Standard deviations were too low to be shown $(<1 \%)$. 


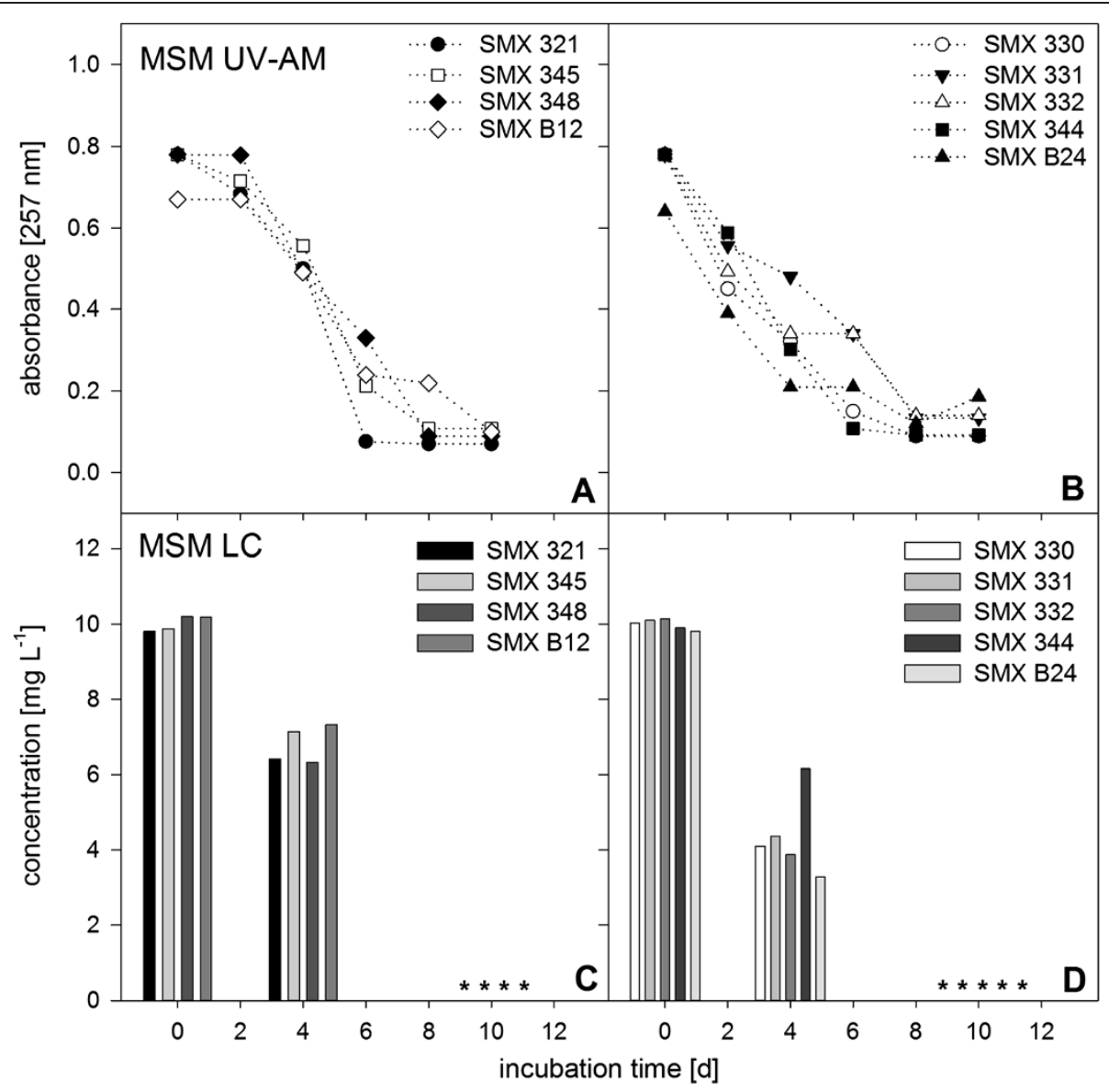

Figure 3 Aerobic SMX biodegradation patterns of pure cultures in MSM media. A, B) measured with UV-AM, initial SMX concentration $10 \mathrm{mg} \mathrm{L}^{-1}$. C, D) LC-UV analyses of SMX concentrations in the pure cultures in MSM at experimental startup, after 4 and 10 days to validate UV-AM. Asterisks indicate measured values below limit of detection. Shown are mean values of SMX absorbance in duplicate experiments. Standard deviations were too low to be shown $(<1 \%)$.

Table 2 Biodegradation rates of the cultures able to biodegrade SMX

\begin{tabular}{|c|c|c|c|c|}
\hline \multirow[t]{2}{*}{ Accession/isolate } & \multirow[t]{2}{*}{ Phylum } & \multicolumn{3}{|c|}{ Biodegradation rate $\left[\mathrm{mg} \mathrm{L}^{-1} \mathrm{~d}^{-1}\right]$} \\
\hline & & R2A-UV & MSM-CN & MSM \\
\hline HF571531, Brevundimonas sp. SMXB12 & Proteobacteria & 2.5 & 1.7 & 1.0 \\
\hline HF571532, Microbacterium sp. SMXB24 & Actinobacteria & 2.5 & 1.25 & 1.25 \\
\hline HF571537, Microbacterium sp. SMX348 & Actinobacteria & 2.5 & 1.7 & 1.25 \\
\hline HF572913, Pseudomonas sp. SMX321 & Proteobacteria & 2.5 & 2.5 & 1.7 \\
\hline HE985241, Pseudomonas sp. SMX330 & Proteobacteria & 2.5 & 1.7 & 1.25 \\
\hline HF571533, Pseudomonas sp. SMX331 & Proteobacteria & 2.5 & 1.7 & 1.25 \\
\hline HF571535, Pseudomonas sp. SMX344 & Proteobacteria & 2.5 & 1.7 & 1.25 \\
\hline HF571536, Pseudomonas sp. SMX345 & Proteobacteria & 2.5 & 1.25 & 1.25 \\
\hline HF571534, Variovorax sp. SMX332 & Proteobacteria & 2.5 & 1.7 & 1.25 \\
\hline
\end{tabular}

*calculated from duplicate experiments $(n=2)$. Standard deviations between duplicate setups were below $1 \%$ and are not shown.

Isolation was performed from an SMX-acclimated AS community, followed by identification with 16S rRNA sequencing. ENA accession numbers and species names are provided. 


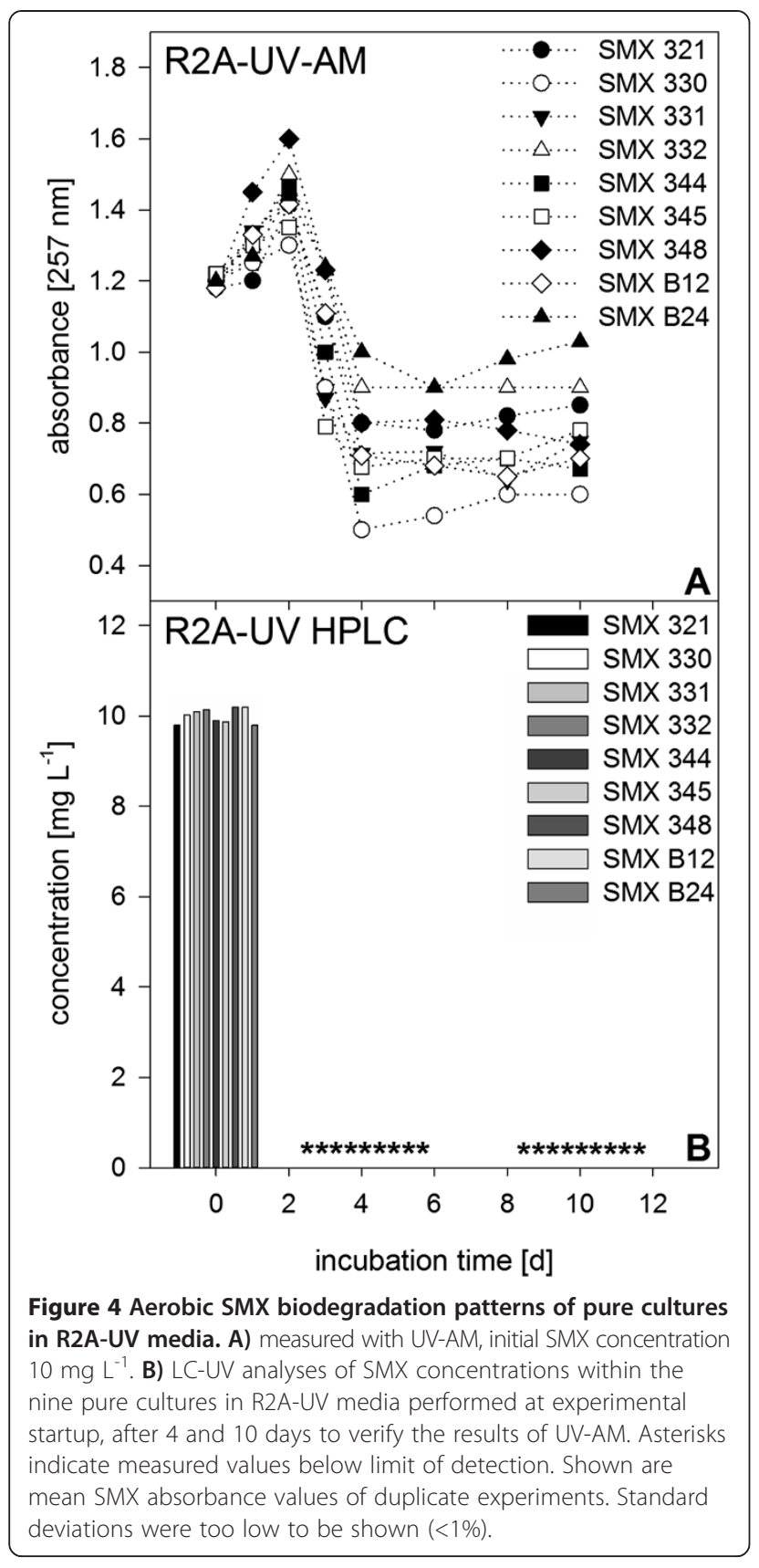

rate of $1.25 \mathrm{mg} \mathrm{L}^{-1} \mathrm{~d}^{-1}$. The same effect was found for the two Microbacterium spp.. While Microbacterium sp. SMXB12 removed SMX with $1.7 \mathrm{mg} \mathrm{L}^{-1} \mathrm{~d}^{-1}$, Microbacterium sp. SMX348 showed a removal of $1.25 \mathrm{mg} \mathrm{L}^{-1} \mathrm{~d}^{-1}$ only. Biodegradation pattern in MSM-CN of four isolates (SMX321, 345, 348 and B12) revealed a short lag phase of two days with no SMX removal (Figure 2A) while the other five were able to biodegrade SMX already after two days and showed a constant SMX removal during cultivation (Figure 2B).

In MSM (Figure 3), with SMX as sole C- and Nsource, the removal rate of SMX was even lower.
Biodegradation rates of $1.0 \mathrm{mg} \mathrm{L}^{-1} \mathrm{~d}^{-1}$ were found for Brevundimonas sp. SMXB12 while Pseudomonas sp. SMX321 showed $1.7 \mathrm{mg} \mathrm{L}^{-1} \mathrm{~d}^{-1}$. All other species showed removal rates of $1.25 \mathrm{mg} \mathrm{L}^{-1} \mathrm{~d}^{-1}$. These experiments with SMX as sole $\mathrm{C} / \mathrm{N}$-source proved that it could serve as nutrient source but with up to 2.5 -fold reduced biodegradation rates. Biodegradation pattern in MSM was similar to that in MSM-CN with a lag phase of two days for the four isolates SMX321, 345, 348 and B12 (Figure 3A) and no lag phase for the isolates SMX 330, 331, 332, 344, and B24 starting to utilize SMX already after two days (Figure 3B). In general it was found that the five Pseudomonas spp. and the two Microbacterium spp. did not show the same biodegradation behavior. At least one member of each group always showed a lag phase while the other immediately started SMX biodegradation.

As UV-AM revealed sufficient to monitor SMX biodegradation (Table 1) LC-UV measurements were only performed at the start of the experiment, day 4 and at day 10 as control measurement (Figures 3B, 4C, D). LC-UV showed that in R2A-UV all cultures removed $10 \mathrm{mg} \mathrm{L}^{-1}$ SMX in 4 days (Figure 2B) while in MSM-CN only Pseudomonas sp. SMX321 removed all SMX within 4 days (Figure 3C). The remaining 8 cultures still showed residual SMX concentrations from 0.4 to $7.3 \mathrm{mg} \mathrm{L}^{-1}$ and complete SMX elimination was achieved only at day 10 (Figure 3C, D). In MSM after 4 days SMX was still present in all nine cultures in concentrations above $3.6 \mathrm{mg} \mathrm{L}^{-1}$ and only after 10 days SMX was below the limit of detection (Figure 4C, D). LC-UV values could be compared to UVAM values and proved this simple approach to be applicable for screening SMX biodegradation.

\section{Discussion and conclusions}

This study focused on the cultivation of pure culture SMX biodegrading organisms to perform specific biodegradation experiments. It is known that cultivation, especially on solid media, is affected with the problem described as "viable but non cultivable" (VBNC) [30,31]. Solid media being implicitly required for the isolation of pure cultures is for sure limited in its cultivation efficiency mainly due to reduced water content and different or inappropriate nutrient conditions. Thus only a low percentage of around $1 \%$ of the active organisms in environmental samples [32] and around 15\% from activated sludge can be cultivated [33,34]. In this study 9 different isolates out of 110 pure cultures were obtained that showed SMX biodegradation. This quite high percentage of almost $10 \%$ was only possible with a two-step SMX-acclimation experiment that was conducted to increase the chance to cultivate SMX biodegrading organisms by applying a strong selective pressure using $10 \mathrm{mg} \mathrm{L}{ }^{-1} \mathrm{SMX}$ in the media. Furthermore, R2A 
medium that is known to work well for isolation of aquatic organisms [35] was applied for the cultivation of bacteria being assumed to be at least SMX-resistant when growth was observed on SMX-reinforced R2A. However, a lot more organisms compared to those cultivated in this study might be present in activated sludge capable of SMX biodegradation. These VBNCs might be taxonomically characterized by culture-independent methods, e.g. restriction fragment length polymorphism screening [36,37]. However, for our focus on linking biodegradation patterns, rates and nutrient utilization to specific species these methods were not feasible. Only with actively biodegrading pure cultures a clear and precise coherence between SMX biodegradation and taxonomically identified species is possible. As a final goal, pure cultures would allow to analyze species-specific biodegradation products and thus determine potential SMX biodegradation pathways. Applying that knowledge to WWTP techniques would provide a strategy to selectively enhance biodegrading species in activated sludge systems improving and stabilizing SMX removal efficiency.

Therefore phylogenetic identification of potential SMX biodegrading species is implicitly required. As shown in this study five of the nine SMX biodegrading species found belonged to the genus Pseudomonas confirming this group to play an important role for the biodegradation of micropollutants. This was proved for e.g. acetaminophen or chlorinated compounds by many other studies [38-40]. Additionally, two isolates SMXB24 and SMX348 were identified as Microbacterium sp.. It was shown that Microbacterium sp. SMXB24 is closely related to Microbacterium sp. $71 \mathrm{~K}$, an organism that was found to be related with phytoremediation. The second Microbacterium sp. SMX348 is closely related to Microbacterium sp. BR1 which was isolated from an acclimated SMX biodegrading membrane bioreactor, proving this species' crucial role for the biodegradation of SMX [29]. In addition the general potential of different Microbacteria species for the biodegradation of xenobiotic compounds has been highlighted in the literature $[41,42]$. Also Variovorax paradoxus, closely related to the isolated Variovorax sp. SMX332, is known from literature to be capable of biodegrading a large variety of pollutants including sulfolene and other heterocyclic compounds [43]. Therefore it seems likely that the isolated Variovorax sp. SMX332 might also be able to biodegrade SMX. Finally, also for the group Brevundimonas spp. some literature data exist proving that these organisms might play a role in the removal of antibiotics [44].

Taxonomic identification was followed by observing influences on biodegradation rate and efficiency due to the availability of nutrients. Biodegradation rates decreased with reduced nutrient content from the complex R2A-UV over nutrient-poor MSM-CN and MSM media and more time was needed to remove SMX. MSM media contained SMX as sole carbon and nitrogen source at a concentration of $10 \mathrm{mg} \mathrm{L}^{-1}$ and thus provided just around $4.8 \mathrm{mg} \mathrm{L}^{-1}$ carbon and $1.7 \mathrm{mg} \mathrm{L}^{-1} \mathrm{ni}-$ trogen. These conditions, with SMX being the only nutrient in MSM, showed an effect on biodegradation and reduced removal efficiency but proved the organisms' ability to utilize SMX as sole nutrient and/or energy source. However, this indicates that complex nutrients and higher nutrient concentrations seem to have a positive effect on biodegradation due to cometabolic [45] or diauxic effects [46] as the very high SMX removal rates of $2.5 \mathrm{mg} \mathrm{L}^{-1} \mathrm{~d}^{-1}$ confirmed that they were significantly higher than the one of $0.0079 \mathrm{mg} \mathrm{L}^{-1}$ $\mathrm{d}^{-1}$ found in a previous study [47].

In general, SMX biodegradation might be based more on a diauxic process, i.e. readily degradable nutrients are used up first followed by SMX utilization, rather than real co-metabolism, i.e. two substrates are used up in parallel when provided together, as experiments with R2A-UV media showed. A strong increase in UV-AM, attributed to biomass growth due to a fast nutrient consumption provided by the complex R2A-UV media, was followed by a rapid SMX elimination. In MSM-CN or MSM, as the nutrients concentrations were too low to foster excessive biomass growth, such an increase was not observed. Even at low cell densities SMX was rapidly removed proving that biomass concentration is not as important as cellular activity. Therefore, the higher removal rates in presence of sufficient nutrients also showed that SMX biodegradation was a rapid and complex metabolic process.

Therefore, information about the biodegradation potential of the isolated bacterial strains with respect to the availability of nutrients might increase the elimination efficiency in WWTPs as the treatment process could be specifically adapted to the needs of the biodegrading species.

For future research, the availability of isolated species will allow screening for biodegradation intermediates and/or stable metabolites and determination of speciesspecific biodegradation pathways. To date only few data on SMX metabolites such as 3-amino-5-methyl-isoxazole found in SMX degrading activated sludge communities [48] and hydroxy-N-(5-methyl-1,2-oxazol-3-yl)benzene-1sulfonamide detected in an SMX degrading consortium of fungi and Rhodococcus rhodochrous exists [45]. Further research is also needed to screen for the nutrient influence on metabolite formation, i.e. if the isolated pure cultures produce different metabolites due to changing nutrient conditions.

\section{Methods}

\section{Chemicals and glassware}

Sulfamethoxazole (SMX, 99.8\% purity) was purchased from Sigma Aldrich (Steinheim, Germany), all other 
organic media components were from Merck KGaA (Darmstadt, Germany) while the inorganic media components were purchased from VWR (Darmstadt, Germany). High-purity water was prepared by a Milli-Q system (Millipore, Billerica, MA, USA). All glassware used was procured from Schott AG (Mainz, Germany) and pre-cleaned by an alkaline detergent (neodisher ${ }^{\circ}$ VWR Darmstadt, Germany) followed by autoclaving for $20 \mathrm{~min}$ at $121^{\circ} \mathrm{C}$.

\section{Activated sludge sampling}

Activated sludge (AS) was taken as grab sample from stage 1 of a 2 -stage municipal conventional activated sludge plant (CAS-M), located near the city of Munich, Germany and treating 1 million populations equivalents. Stage 1 is the high load stage with a food to microorganism ratio of $0.64 \mathrm{~kg} \mathrm{BOD} \mathrm{kg}^{-1} \mathrm{MLSS}^{-1}$. The influent consists of municipal and industrial wastewater (1:1). $500 \mathrm{~mL}$ AS (SMX concentration $600 \mathrm{ng} \mathrm{L}^{-1}$ ) were collected in pre-cleaned $1 \mathrm{~L}$ glass bottles, stored at $4^{\circ} \mathrm{C}$ and used within $24 \mathrm{~h}$ for inoculation of the different setups.

\section{Experimental setup \\ SMX acclimated ASC}

Evaluation of AS biodegradation potential obtained from the WWTP, was performed in $150 \mathrm{~mL}$ R2A-UV media (casein peptone $1,000 \mathrm{mg} \mathrm{L}^{-1}$, glucose $500 \mathrm{mg} \mathrm{L}^{-1}$, potassium phosphate $300 \mathrm{mg} \mathrm{L}^{-1}$, soluble starch $300 \mathrm{mg} \mathrm{L}^{-1}$, DOC:N ratio 7:1, $\mathrm{pH} 7.4$ ), spiked with $10 \mathrm{mg} \mathrm{L}^{-1} \mathrm{SMX}$ to apply a high selective pressure. Non-SMX-resistant organisms were ruled out and the chance to obtain SMX biodegrading organisms was increased in subsequent isolation steps. After biodegradation occurred the experiment was stopped and the remaining biomass was used to inoculate a second setup under the same conditions to further decrease microbial diversity and favor SMX-resistant/biodegrading organisms. After the second setup showed biodegradation, the experiment was stopped and the biomass used for cultivation of SMX biodegrading organisms on solid R2A-UV media (1.5\% agar supply). SMX removal was determined by UV-absorbance measurements (UV-AM) as fast pre-screening method for biodegradation (see 2.4.1).

\section{Cultivation and isolation of pure cultures}

Pure cultures were successfully cultivated and isolated from SMX-acclimated biodegrading ASC. $200 \mu \mathrm{L}$ AS was plated on solid R2A-UV media containing $10 \mathrm{mg} \mathrm{L}^{-1}$ SMX to inhibit growth of non-resistant bacteria and foster growth of potential SMX-resistant/biodegrading organisms. After cultures were observed on solid media they were isolated and further purified by streaking on new plates resulting in 110 isolates. These were used for inoculation of $100 \mathrm{~mL}$ setups with $20 \mathrm{~mL}$ MSM-CN media
$\left(\mathrm{KH}_{2} \mathrm{PO}_{4} 80 \mathrm{mg} \mathrm{L}{ }^{-1}, \mathrm{~K}_{2} \mathrm{HPO}_{4} 200 \mathrm{mg} \mathrm{L}{ }^{-1}, \mathrm{Na}_{2} \mathrm{HPO}_{4}\right.$ $300 \mathrm{mg} \mathrm{L}^{-1}, \mathrm{MgSO}_{4} * 7 \mathrm{H}_{2} \mathrm{O} 20 \mathrm{mg} \mathrm{L}^{-1}, \mathrm{CaCl}^{*} 2 \mathrm{H}_{2} \mathrm{O}$ $40 \mathrm{mg} \mathrm{L}^{-1}, \mathrm{FeCl}_{3}{ }^{*} 6 \mathrm{H}_{2} \mathrm{O} 0.3 \mathrm{mg} \mathrm{L}^{-1}$, sodium acetate $300 \mathrm{mg} \mathrm{L}^{-1}$ and $\mathrm{NH}_{4} \mathrm{NO}_{3} 7.5 \mathrm{mg} \mathrm{L}^{-1}$, DOC: $\mathrm{N}$ ratio 33:1, $\mathrm{pH}$ 7.4) spiked with $10 \mathrm{mg} \mathrm{L}^{-1}$ SMX. Setups were monitored with UV-AM (see 2.4.1) for possible biodegradation. Isolates showing biodegradation were further identified by $16 \mathrm{~S}$ rRNA gene sequence analysis (see 2.5).

\section{Biodegradation setups with pure cultures}

Batch experiments were performed to A) screen for biodegradation potential in the isolated cultures and $\mathrm{B}$ ) determine differences in SMX biodegradation pattern and rate concerning the availability of nutrients. Three media, R2A-UV, MSM-CN and MSM (as MSM-CN but without sodium acetate and $\mathrm{NH}_{4} \mathrm{NO}_{3}$ ) were used and inoculated with pure cultures in $100 \mathrm{~mL}$ setups filled with $20 \mathrm{~mL}$ of media spiked with $10 \mathrm{mg} \mathrm{L}^{-1} \mathrm{SMX}$. Duplicate setups $(n=2)$ including sterile, i.e. autoclaved biomass and abiotic, i.e. without biomass, controls for each medium were prepared. Aerobic conditions and photolysis prevention were ensured by shaking at $150 \mathrm{rpm}$ on an orbital shaker in the dark.

The setups were sampled once a day for MSM-CN and MSM media and twice a day for R2A-UV, by taking $1 \mathrm{~mL}$ supernatant after half an hour of sedimentation that was sufficient to ensure not to withdraw much biomass. $200 \mu \mathrm{L}$ was used for UV-AM and $800 \mu \mathrm{L}$ for LC-UV measurements.

\section{Analyses of sulfamethoxazole UV-AM}

$200 \mu \mathrm{L}$ were taken from the setups and directly used for UV-AM as described elsewhere (Herzog et al., submitted) with the following changes applied. Calibration was performed with 1.0, 5.0, 10.0 and $15.0 \mathrm{mg} \mathrm{L}^{-1} \mathrm{SMX}$ in high-purity water and the used media to evaluate measurement reliability and background absorbance. 96 well UV-star plates from Greiner Bio-One (Greiner Bio-One $\mathrm{GmbH}$, Frickenhausen, Germany) filled with $200 \mu \mathrm{L}$ were used for measurements and analyzed with an automated plate reader (EnSpire ${ }^{\oplus}$ Multimode Plate Reader, Perkin Elmer, Rodgau, Germany). Each measurement included an SMX blank (media with SMX but without organisms) was measured to detect changes over time as well as a blank (media without SMX) to detect background absorbance.

\section{LC-UV analysis}

$800 \mu \mathrm{L}$ samples obtained from the setups were centrifuged $\left(10 \mathrm{~min}, 8000 \mathrm{~g}, 20^{\circ} \mathrm{C}\right)$, filtrated through a $0.45 \mu \mathrm{m}$ membrane filter to remove cellular debris and biomass and filled into sterile glass flasks. Flasks were stored at $-20^{\circ} \mathrm{C}$ before analysis. 
Analysis was performed with a Dionex 3000 series HPLC system (Dionex, Idstein, Germany), equipped with an auto sampler. A DAD scanning from 200 to $600 \mathrm{~nm}$ was applied to detect and quantify SMX. Chromatographic separation was achieved on a Nucleosil 120-3 C18 column $(250 \mathrm{~mm} \times 3.0 \mathrm{~mm}$ i.d., $3 \mu \mathrm{m}$ particle size $)$ from Macherey Nagel (Düren, Germany) at a column temperature of $25^{\circ} \mathrm{C}$. The applied mobile phases were acetonitrile (AN) and water $(\mathrm{pH} 2.5$ using phosphoric acid). The gradient used for the first 5 min was $7 \% \mathrm{AN}$ followed by $7-30 \%$ AN from $5-18$ min, $30 \%$ AN for minutes $18-30$ and finally $7 \%$ AN for minutes $30-35$. The solvent flow rate was $0.6 \mathrm{~mL} \mathrm{~min}{ }^{-1}$. The column was allowed to equilibrate for $5 \mathrm{~min}$ between injections. Limit of quantification and limit of detection were $0.1 \mathrm{mg} \mathrm{L}^{-1}$ and $0.03 \mathrm{mg} \mathrm{L}^{-1}$, respectively.

\section{Taxonomic and phylogenetic identification of isolated pure cultures by $16 \mathrm{~S}$ rRNA gene sequence analysis}

DNA of SMX biodegrading organisms was extracted by a standard phenol/chloroform/CTAB extraction method. 16S rRNA gene was subsequently amplified via standard PCR using universal bacterial primers 27f (5-AGA GTT TGA TCM TGG CTC AG-3) and 1492r (5-TAC GGY TAC CTT GTT ACG ACT T-3) [49]. All cultures were sent to MWG Operon (Ebersberg, Germany) for sequencing using again primers $27 \mathrm{f}$ and $1492 \mathrm{r}$ and resulting in nearly full length $16 \mathrm{~S}$ rRNA gene sequences. Sequences were analyzed with and submitted to European Nucleotide Archive (http://www.ebi.ac.uk/ena/) to receive accession numbers (Table 2).

Subsequent phylogenetic analysis was accomplished with the sequences using the alignment and tree calculation methods of the ARB software package [50]. The nearly complete 16S rRNA gene sequences of the species isolated in this study and their corresponding published closest relatives (http://blast.ncbi.nlm.nih.gov/Blast.cgi) were added to an existing ARB-alignment for the 16S rRNA gene sequence. Alignment was performed with the CLUSTAL $\mathrm{W}$ implemented in ARB. Phylogenetic trees of the $16 \mathrm{~S}$ rRNA gene sequences were calculated based on maximum likelihood.

\section{Competing interest}

The authors declare that there are no competing interests.

\section{Authors' contributions}

$\mathrm{BH}$ drafted the manuscript, designed and carried out the biodegradation experiments. $\mathrm{HL}$ reviewed the manuscript. $\mathrm{HH}$ and EM conceived of the study, participated in its coordination and helped to review the manuscript. All authors read and approved the final manuscript.

\section{Acknowledgement}

Financial support by the Bavarian State Ministry of the Environment and Public Health (StMUG) is gratefully acknowledged.

\section{Author details}

'Chair of Urban Water Systems Engineering, Technische Universität München, Am Coulombwall, D-85748 Garching, Germany. ²Bavarian Environment Agency, Bürgermeister-Ulrich-Str. 160, D-86179 Augsburg, Germany. ${ }^{3}$ Karlsruhe Institute of Technology, Engler-Bunte-Institut, Bereich Wasserchemie und Wassertechnologie, D-76131 Karlsruhe, Germany.

Received: 23 August 2013 Accepted: 18 November 2013

Published: 1 December 2013

\section{References}

1. Kümmerer K: Pharmaceuticals in the environment: sources, fate, effects, and risks. 2nd edition. Berlin, Heidelberg, Germany: Springer; 2004

2. Kümmerer K: Pharmaceuticals in the environment. 3rd, Revised and enlarged Edition edn. Berlin, Heidelberg, Germany: Springer; 2008.

3. Baran W, Sochacka J, Wardas W: Toxicity and biodegradability of sulfonamides and products of their photocatalytic degradation in aqueous solutions. Chemosphere 2006, 65:1295-1299.

4. Xu B, Mao D, Luo Y, Xu L: Sulfamethoxazole biodegradation and biotransformation in the water-sediment system of a natural river. Bioresour Technol 2011, 102:7069-7076.

5. Heberer T: Occurrence, fate, and removal of pharmaceutical residues in the aquatic environment: a review of recent research data. Toxicol Lett 2002, 131:5-17.

6. Ternes T, Joss A: Human pharmaceuticals, hormones and fragrances the challenge of micropollutants in urban water management. ; 2007.

7. Kümmerer K: Antibiotics in the aquatic environment-a review-part I. Chemosphere 2009, 75:417-434.

8. Kümmerer K: Antibiotics in the aquatic environment-a review-part II. Chemosphere 2009, 75:435-441.

9. Pérez S, Eichhorn P, Aga DS: Evaluating the biodegradability of sulfamethazine, sulfamethoxazole, sulfathiazole, and trimethoprim at different stages of sewage treatment. Environ Toxicol Chem 2005, 24:1361-1367

10. Hoa PTP, Managaki S, Nakada N, Takada H, Shimizu A, Anh DH, Viet PH, Suzuki S: Antibiotic contamination and occurrence of antibiotic-resistant bacteria in aquatic environments of northern Vietnam. Sci Total Environ 2011, 409:2894-2901

11. Agerso $Y$, Petersen A: The tetracycline resistance determinant Tet 39 and the sulphonamide resistance gene sulll are common among resistant Acinetobacter spp. isolated from integrated fish farms in Thailand. J Antimicrob Chemother 2007, 59:23-27.

12. Szczepanowski R, Linke B, Krahn I, Gartemann K-H, Gützkow T, Eichler W, Pühler A, Schlüter A: Detection of 140 clinically relevant antibioticresistance genes in the plasmid metagenome of wastewater treatment plant bacteria showing reduced susceptibility to selected antibiotics. Microbiology 2009, 155:2306-2319.

13. Cavallucci S: Top 200: What's topping the charts in prescription drugs this year Pharmacy practice, Canadian Healthcare Network. 2007

14. Benotti MJ, Trenholm RA, Vanderford BJ, Holady JC, Stanford BD, Snyder SA: Pharmaceuticals and endocrine disrupting compounds in US drinking water. Environ Sci Technol 2008, 43:597-603.

15. Miège $C$, Choubert J, Ribeiro $L$, Eusèbe $M$, Coquery $M$ : Fate of pharmaceuticals and personal care products in wastewater treatment plants-Conception of a database and first results. Environ Pollut 2009, 157:1721-1726.

16. Sacher F, Lange FT, Brauch HJ, Blankenhorn I: Pharmaceuticals in groundwaters: analytical methods and results of a monitoring program in Baden-Wurttemberg, Germany. J Chromatogr 2001, 938:199-210.

17. Onesios K, Yu J, Bouwer E: Biodegradation and removal of pharmaceuticals and personal care products in treatment systems: a review. Biodegradation 2009, 20:441-466.

18. Huang T-S, Kunin CM, Yan B-S, Chen Y-S, Lee SS-J, Syu W: Susceptibility of Mycobacterium tuberculosis to sulfamethoxazole, trimethoprim and their combination over a 12 year period in Taiwan. J Antimicrob Chemother 2012, 67:633-637.

19. Fajardo A, Martínez JL: Antibiotics as signals that trigger specific bacterial responses. Curr Opin Microbiol 2008, 11:161-167.

20. Jiang $X$, Shi L: Distribution of tetracycline and trimethoprim/ sulfamethoxazole resistance genes in aerobic bacteria isolated from cooked meat products in Guangzhou, China. Food Control 2013, 30:30-34. 
21. Liu F, Wu J, Ying G-G, Luo Z, Feng $\mathrm{H}$ : Changes in functional diversity of soil microbial community with addition of antibiotics sulfamethoxazole and chlortetracycline. Appl Microbiol Biotechnol 2012, 95:1615-1623.

22. Gutiérrez I, Watanabe N, Harter T, Glaser B, Radke M: Effect of sulfonamide antibiotics on microbial diversity and activity in a Californian Mollic Haploxeralf. J Soils Sed 2010, 10:537-544.

23. Collado N, Buttiglieri G, Marti E, Ferrando-Climent L, Rodriguez-Mozaz S, Barceló D, Comas J, Rodriguez-Roda I: Effects on activated sludge bacterial community exposed to sulfamethoxazole. Chemosphere 2013, 93:99-106.

24. Göbel A, McArdell CS, Joss A, Siegrist H, Giger W: Fate of sulfonamides, macrolides, and trimethoprim in different wastewater treatment technologies. Sci Total Environ 2007, 372:361-371.

25. Niu J, Zhang L, Li Y, Zhao J, Lv S, Xiao K: Effects of environmental factors on sulfamethoxazole photodegradation under simulated sunlight irradiation: kinetics and mechanism. J Environ Sci 2013, 25:1098-1106.

26. Trovó AG, Nogueira RFP, Agüera A, Sirtori C, Fernández-Alba AR: Photodegradation of sulfamethoxazole in various aqueous media: persistence, toxicity and photoproducts assessment. Chemosphere 2009, 77:1292-1298.

27. Hyland KC, Dickenson ERV, Drewes JE, Higgins CP: Sorption of ionized and neutral emerging trace organic compounds onto activated sludge from different wastewater treatment configurations. Water Res 2012, 46:1958-1968.

28. Ludwig W, Klenk H-P: Overview: a phylogenetic backbone and taxonomic framework for procaryotic systematics. In Bergey's manual ${ }^{\circledR}$ of systematic bacteriology. Edited by Boone D, Castenholz R. New York: Springer; 2001:49-65.

29. Bouju H, Ricken B, Beffa T, Corvini PF, Kolvenbach BA: Isolation of bacteria strains capable of sulfamethoxazole mineralization from an acclimated membrane bioreactor. Appl Environ Microbiol 2012, 78:277-279.

30. Jiang $Q$, Fu B, Chen Y, Wang Y, Liu H: Quantification of viable but nonculturable bacterial pathogens in anaerobic digested sludge. Appl Microbiol Biotechnol 2013, 97:6043-6050.

31. Wagner M, Assmus B, Hartmann A, Hutzler P, Amann R: In situ analysis of microbial consortia in activated sludge using fluorescently labelled, rRNA-targeted oligonucleotide probes and confocal scanning laser microscopy. J Microsc 1994, 176:181-187.

32. Vartoukian SR, Palmer RM, Wade WG: Strategies for culture of 'unculturable' bacteria. FEMS Microbiol Lett 2010, 309:1-7.

33. Wagner $M$, Amann $R$, Lemmer $H$, Schleifer $\mathrm{KH}$ : Probing activated sludge with oligonucleotides specific for proteobacteria: inadequacy of culturedependent methods for describing microbial community structure. Appl Environ Microbiol 1993, 59:1520-1525.

34. Snaidr J, Amann R, Huber I, Ludwig W, Schleifer KH: Phylogenetic analysis and in situ identification of bacteria in activated sludge. Appl Environ Microbiol 1997, 63:2884-2896.

35. Reasoner DJ, Geldreich EE: A new medium for the enumeration and subculture of bacteria from potable water. Appl Environ Microbiol 1985 49:1-7.

36. Chiellini C, Munz G, Petroni G, Lubello C, Mori G, Verni F, Vannini C: Characterization and comparison of bacterial communities selected in conventional activated sludge and membrane bioreactor pilot plants: a focus on nitrospira and planctomycetes bacterial phyla. Curr Microbiol 2013, 67:77-90.

37. Wells GF, Park H-D, Eggleston B, Francis CA, Criddle CS: Fine-scale bacterial community dynamics and the taxa-time relationship within a full-scale activated sludge bioreactor. Water Res 2011, 45:5476-5488

38. Larcher S, Yargeau V: Biodegradation of sulfamethoxazole by individual and mixed bacteria. Appl Microbiol Biotechnol 2011, 91:211-218.

39. De Gusseme B, Vanhaecke L, Verstraete W, Boon N: Degradation of acetaminophen by delftia tsuruhatensis and pseudomonas aeruginosa in a membrane bioreactor. Water Res 2011, 45:1829-1837.

40. Tezel U, Tandukar M, Martinez RJ, Sobecky PA, Pavlostathis SG: Aerobic biotransformation of $n$-tetradecylbenzyldimethylammonium chloride by an enriched pseudomonas spp. Community. Environ Sci Technol 2012, 46:8714-8722

41. Shiomi N, Ako M: Biodegradation of melamine and cyanuric acid by a newly-isolated microbacterium strain. Adv Microbiol 2012, 2:303-309.

42. Chunming W, Chunlian LIDW: Biodegradation of naphthalene, phenanthrene, anthracene and pyrene by microbacterium sp. 3-28. Chin J Appl Environ Biol 2009, 3:017.
43. Satola B, Wübbeler J, Steinbüchel A: Metabolic characteristics of the species variovorax paradoxus. Appl Microbiol Biotechnol 2013, 97:541-560

44. Islas-Espinoza M, Reid B, Wexler M, Bond P: Soil bacterial consortia and previous exposure enhance the biodegradation of sulfonamides from Pig manure. Microb Ecol 2012, 64:140-151

45. Gauthier $H$, Yargeau V, Cooper DG: Biodegradation of pharmaceuticals by rhodococcus rhodochrous and aspergillus niger by co-metabolism. Sci Total Environ 2010, 408:1701-1706.

46. Cohen GN: Bacterial growth. In Microbial biochemistry. Dordrech, Netherlands: Springer; 2011:1-10.

47. Yang S-F, Lin C-F, Wu C-J, Ng K-K, Yu-Chen Lin A, Andy Hong P-K: Fate of sulfonamide antibiotics in contact with activated sludge-sorption and biodegradation. Water Res 2012, 46:1301-1308.

48. Müller $\mathrm{E}$, Schüssler W, Horn H, Lemmer H: Aerobic biodegradation of the sulfonamide antibiotic sulfamethoxazole by activated sludge applied as co-substrate and sole carbon and nitrogen source. Chemosphere 2013, 92:969-978.

49. Weisburg WG, Barns SM, Pelletier DA, Lane DJ: 16S ribosomal DNA amplification for phylogenetic study. J Bacteriol 1991, 173:697-703.

50. Ludwig W, Strunk O, Westram R, Richter L, Meier H, Buchner A, Lai T, Steppi $S$, Jobb G, Yadhukumar, et al: ARB: a software environment for sequence data. Nucleic Acids Res 2004, 32:1363-1371.

doi:10.1186/1471-2180-13-276

Cite this article as: Herzog et al:: Characterization of pure cultures isolated from sulfamethoxazole-acclimated activated sludge with respect to taxonomic identification and sulfamethoxazole biodegradation potential. BMC Microbiology 2013 13:276.

\section{Submit your next manuscript to BioMed Central and take full advantage of:}

- Convenient online submission

- Thorough peer review

- No space constraints or color figure charges

- Immediate publication on acceptance

- Inclusion in PubMed, CAS, Scopus and Google Scholar

- Research which is freely available for redistribution 